\title{
Papillary Carcinoma in Thyroglossal Cyst
}

\author{
${ }^{1}$ Gautam Khaund, ${ }^{2}$ Vivek Agarwal, ${ }^{3}$ Surajit Barman, ${ }^{4}$ Debika Baruah, ${ }^{5}$ Biswajit Gogoi
}

\begin{abstract}
Thyroglossal duct cysts are not uncommon but malignancy in such a cyst is infrequent. Two patients of thyroglossal duct cyst papillary carcinoma are presented here. Both of these patients had different risk profiles and were managed differently. Both the patients have been followed up for 5 years and have shown no recurrences.
\end{abstract}

Keywords: Papillary carcinoma, Thyroglossal cyst, Malignancy.

How to cite this article: Khaund G, Agarwal V, Barman S, Baruah D, Gogoi B. Papillary Carcinoma in Thyroglossal Cyst. Int J Phonosurg Laryngol 2014;4(2):69-70.

\section{Source of support: Nil}

Conflict of interest: None

\section{INTRODUCTION}

Thyroglossal cysts are common occurrences. Seventy percent of thyroglossal duct cysts are diagnosed in childhood, $7 \%$ are diagnosed in adulthood. These cysts arise due to persistence of a portion of the thyroglossal duct. Thyroid tissue is present in the cyst wall in more than $60 \%$ of cases. ${ }^{6}$ Papillary carcinoma of the thyroglossal duct cyst is rare. ${ }^{7}$ Around 250 odd cases have been reported in world literature.

We present here two patients of papillary carcinoma of thyroglossal duct cyst. Both were managed by surgery only but with slightly different strategies.

\section{CASE REPORTS}

\section{Case 1}

A 35-year-old young man presented with a neck swelling. It was in the midline, moved up with deglutition and on protruding the tongue. It was painless. It measured approximately $2 \times 1 \mathrm{~cm}$. There were no other palpable nodes in the neck and no other abnormality was detected in the ENT examination. A clinical diagnosis of a thyroglossal duct cyst was made. Ultrasound examination revealed 'a well-defined cytic lesion approximately $22 \times 13 \mathrm{~mm}$ in

\footnotetext{
${ }^{1}$ Chief Consultant, ${ }^{2-5}$ Consultant

${ }^{1-4}$ Department of ENT, Nightingale Hospital, Guwahati, Assam, India

${ }^{5}$ Department of ENT, Pratiksha Hospital, Guwahati, Assam, India

Corresponding Author: Gautam Khaund, Chief Consultant Department of ENT, Nightingale Hospital, Guwahati-781005 Assam, India, e-mail:gautamkhaund@rediffmail.com
}

the infrahyoid neck. There is a large intramural nodule inside the cystic lesion. It shows tiny calcification and internal vascularity. Impression: Thyroglossal duct cyst with possible malignant transformation' (Fig. 1).

Fine needle aspiration cytology (FNAC) comment was 'thyroglossal cyst with neoplastic transformation cannot be ruled out'. The thyroid profile of the patient was normal. He was accordingly prepared for surgery under general anesthesia (GA). The patient underwent a Sistrunk procedure where the cyst along with the tract, a segment of the body of the hyoid and a cuff of tissue from the central tongue base was excised. The final histopathology report revealed 'papillary carcinoma of thyroid gland' (Fig. 2). The patient did not receive any other treatment. He was on regular follow-up for the last 5 years without any recurrence.

\section{Case 2}

A 58-year-old diabetic lady complained of a swelling in front of the neck which she had noticed for a few years. But, the swelling had recently increased in size. It was painless, mobile. It moved up with swallowing and on protruding the tongue. Ultrasonography (USG) revealed a complex cystic mass lesion $3 \times 2 \mathrm{~cm}$. It was separate from the thyroid gland abutting the isthmus. It showed solid and cystic components. The cystic component shows tiny punctuate calcification and internal vascularity. The possibility was malignant transformation of a thyroglossal cyst (cystic papillary carcinoma)'(Fig. 3).

Fine needle aspiration cytology suspected a papillary thyroid carcinoma with cystic change. Considering the

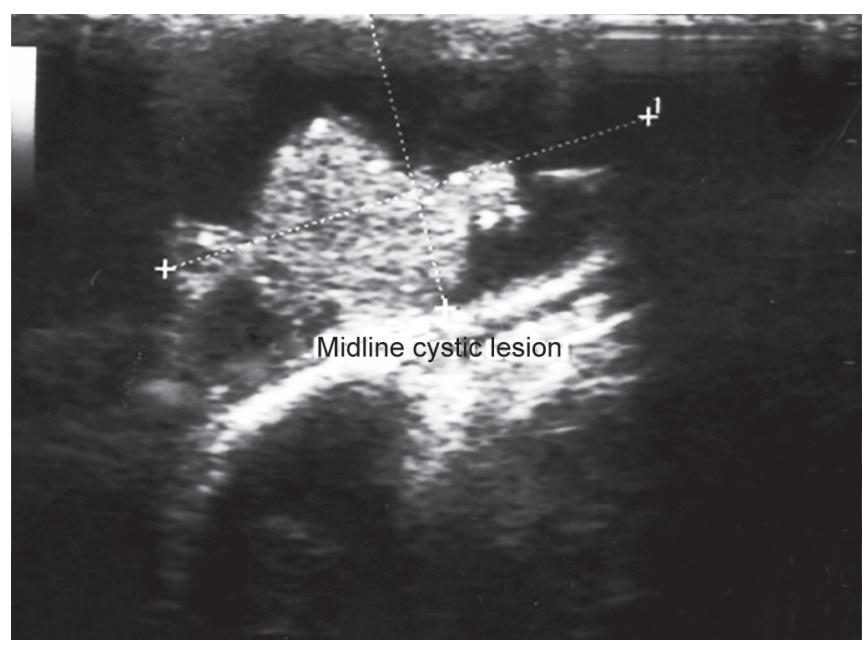

Fig. 1: Ultrasonography of thyroglossal cyst of case 1 


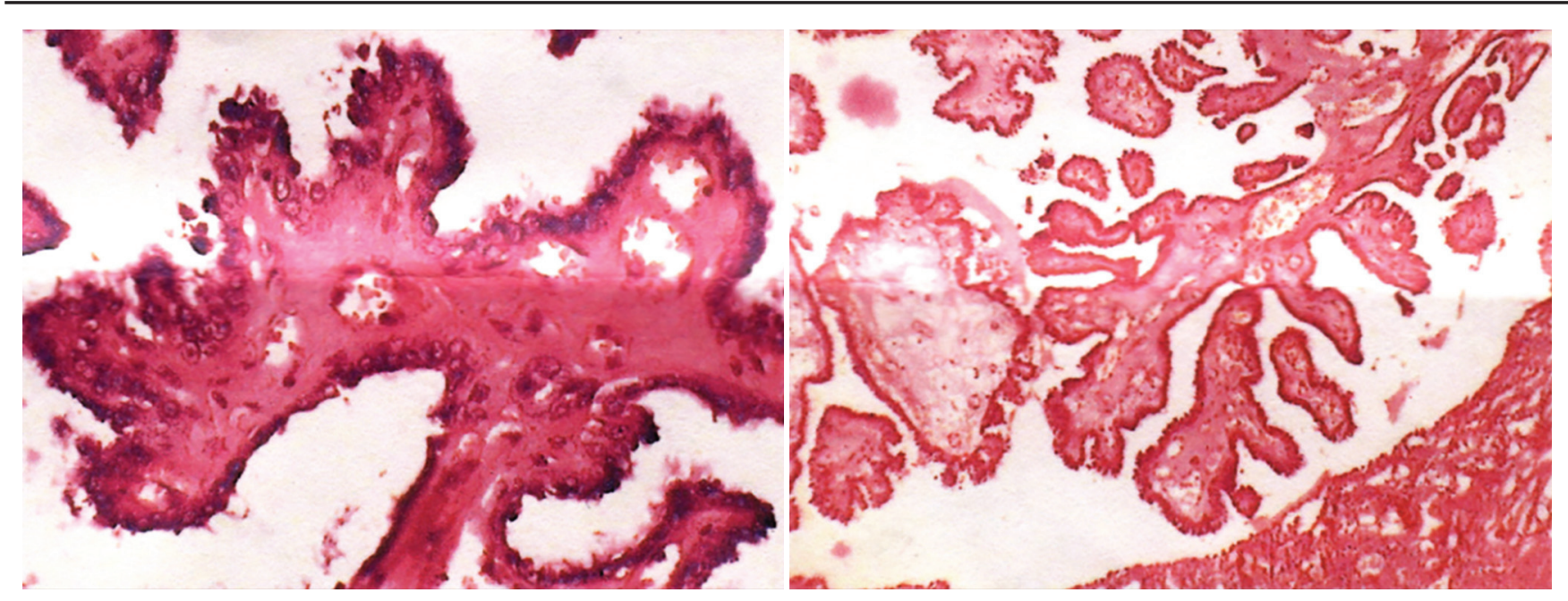

Fig. 2: Histopathological examination photograph of case 1 showing papillary carcinoma thyroid

risk profile of the patient, we planned her for surgery under GA. The patient underwent a total thyroidectomy, Sistrunk procedure and lateral and central compartment neck clearance.

The postoperative period was uneventful. The histopathological examination (HPE) report revealed papillary carcinoma only in the cyst wall.The thyroid gland and all the nodes were free of disease. A radioiodine scan of the patient was done which did not show any residual thyroid tissue. This patient needed thyroxine replacement postoperatively. She also has been followed up for the past 5 years and there is no recurrence.

\section{DISCUSSION}

Carcinoma of thyroglossal duct cyst is uncommon. About 260 cases have been reported in world literature. Earlier it was hypothesized that differentiated thyroid tumors in association with thyroglossal duct were due to metastasis or invasion from a primary thyroid carcinoma. ${ }^{3}$ Later studied by Batsakis, ${ }^{2}$ Kristensen et $\mathrm{al}^{4}$ observed that thyroid carcinoma may arise de novo in thyroglossal remnants. Though a diagnosis of thyroglossal duct carcinoma is rarely made clinically, with better USG studies and experienced cytologist's it may be possible to suspect or diagnose the same preoperatively.

Papillary carcinoma of the thyroglossal duct is not a very aggressive disease. The biological behavior is similar to that of papillary carcinoma of the thyroid gland. ${ }^{1}$ Microscopic focus of papillary carcinoma in a thyroglossal cyst without cyst wall invasion can be managed by Sistrunk's operation alone. ${ }^{8}$ More extensive involvement of the cyst and the thyroid gland would require a total thyroidectomy. ${ }^{5}$ In instances of nodal metastasis, a neck dissection may be needed. Recurrences or residual disease can be managed by surgery or radioiodine therapy. ${ }^{7}$ Long-term close follow-up of the patients is advisable.
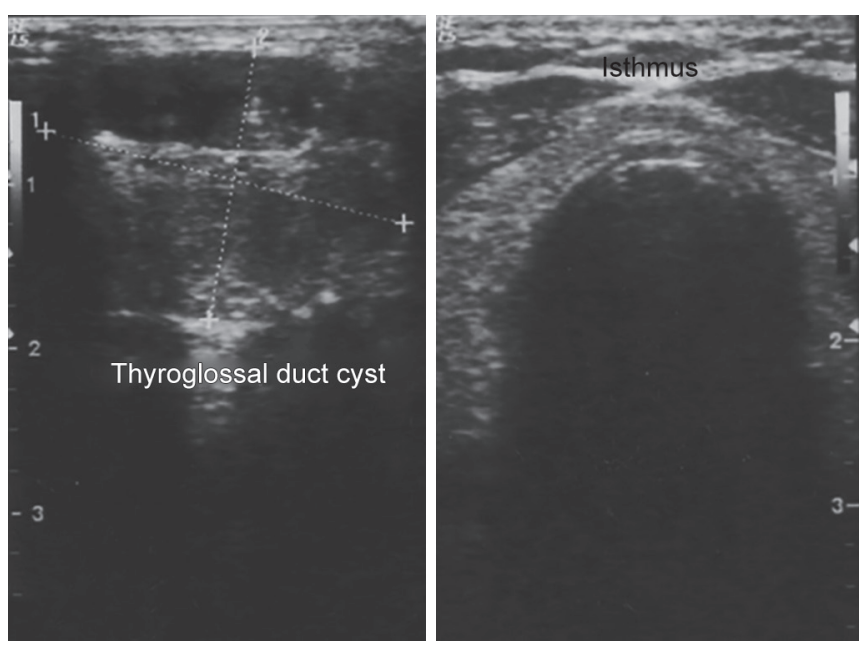

Fig. 3: Ultrasonography photograph of case 2

\section{REFERENCES}

1. Thakar A, Tandon DA, Sharma S. Papillary carcinoma in a thyroglossal cyst: report of a case and review of literature. Ind J Otolaryngol Head Neck Surgery 1999;51(4):86-88.

2. Batsakis JG.Tumours of the head and neck: clinical and pathological consideration. 2nd ed. William and Wilkins, Baltimore; 1979. p. 237.

3. Judd ES. Thyroglossal duct cyst and sinuses. Surgical clinics of North America 1963;43:1023-1032.

4. Kristensen S, Juul A, Moesner J. Thyroglossal duct carcinoma.J Laryngol Otology 1984;98:1277-1280.

5. Kennedy TL,Whitaker M, Wadih G. Thyroglossal duct carcinoma: a rational approach to management. Laryngoscope 1998;108:1154-1158.

6. Maran AGD. Benign diseases of neck. In: Kerr AG, Hibberts J, editors. Scott Brown's Otolaryngology. 6th ed. Oxford: Butterworth-Heinemann; 5/16/2, 1997.

7. Eryilmaz MA, Toy H. Primary papillary thyroid carcinoma in the thyroglossal cyst: over 80 months follow-up. Euro J General Med 2011;8(1):69-71.

8. Ramalingam R, Ramalingam KK, Ramesh AV, Prabhu SM, Vergis M, Ahilaswamy N. Papillary thyroid carcinoma in a thyroglossal cyst. Ind J Otolaryngol Head Neck Surg 2003;55(4):294-295 